\title{
Kant e a estrutura orgânica da razão ${ }^{1}$
}

\author{
Pedro Paulo Garrido Pimenta \\ Universidade de São Paulo \\ pgpimenta@yahoo.com.br
}

resumo 0 objetivo do texto é sugerir que Kant concebe uma instância de regulação do discurso filosófico que se institui no mesmo movimento reflexivo de constituição daquilo que se chama, na filosofia crítica, de transcendental. Para tanto, abordamos uma metáfora conhecida dos leitores da Crítica da razão pura, a estrutura orgânica da razão.

palavras-chave Transcendental; Linguagem; Estrutura, Figuração; Razão

Era o que ele estudava. "A estrutura, quer dizer, a estrutura"ele repetia e abria a mão branquíssima ao esboçar o gesto redondo.

Eu ficava olhando seu gesto impreciso

porque uma bolha de sabão é mesmo imprecisa, nem sólida, nem líquida, nem realidade nem sonho.

Película e oco. (TELLES, 1998, p. 139)

As passagens da Crítica da razão pura nas quais Kant se serve de linguagem metafórica são poucas e bem conhecidas: lembremos aqui o "tribunal da Recebido em 10 de dezembro de 2007. Aceito em 17 de janeiro de 2008. doispontos, Curitiba, São Carlos, vol. 5, n. 1, p.123-138, abril, 2008 


\section{4}

crítica", o entendimento como um "país, a terra da verdade", ou a "razão orgânica". Essas figuras de linguagem, justamente famosas, destacam-se em textos densos e difíceis, ma rados pelo uso rigoroso de uma term inologia técnica da qual o leitor deve se apoderar se quiser compreender o argumento. Daí a dificuldade enfrentada por todo aquele que se arrisca na leitura de Kant: um texto hermético, aparentemente insondável, quiçá auto-referente. Diante disso, cabe perguntar: em que termos se torna possível e justificável, para Kant, um afrouxamento da linguagem tal como o que ocorre quando o filósofo escolhe falar por imagens?

O próprio Kant não deixa dúvidas quanto à importância do registro figurado para a sua filosofia. O autor da Crítica da razão pura reconhece, desde o prefácio à primeira edição dessa obra, que "o leitor tem o direito de exigir" de um livro de filosofia que ele tenha "cla reza discursiva, por conceitos" (clarza lógica) e "clareza intuitiva, por intuições" (clareza estética) (KANT, 1987, p. A XVII). Desculpa-se a seguir por nem sempre ter respondido a esta segunda exigência. A segunda edição da Crítica traz substanciais modificações, seja na "forma da exposição", seja no conteúdo; mas não, segundo Kant, "nas proposições e provas mesmas", nem "na forma e conjunto do plano da obra" (KANT, 1987, p. B XXXIV e XXXVII). As alterações, reconhece o autor, talvez imponham ao leitor, especialmente ao leitor atento, uma tarefa ainda mais árdua na compreensão da obra. A contraparte oferecida por Kant é uma "exposição mais compreensível”, ou seja, mais precisa e certeira (KANT, 1987, p. B XLII). Essas alterações, como se sabem, dizem respeito principalmente à Dedução das categorias e aos Paralogismos da alma, textos que se tornam mais curtos e provavelmente mais dificeis. Em todo caso, alterações expositivas de ordem lógica, não estética, que tornam a obra mais dificil, não mais fácil.

É razoável supor que o empenho de Kant em aprimorar a clareza expositiva por conceitos na segunda edição de sua obra o tenha impedido, ainda uma vez, de torná-la mais acessível ao leitor. E é questionável se isso seria possível, ou mesmo desejável. Kant sublinha, no prefácio que redige especialmente para essa segunda edição, que seria um erro supor que a crítica se opõe ao "procedimento dogmático da razão»; o que ela rejeita é o "dogmatismo da razão», fiando-se entretanto pelos preceitos escolásticos da exposição filosófica (KANT, 1987, p. B XXXV-XXXVI)². Sendo assim, recursos de estilo que tornassem o texto mais didático, tais 
como imagens, exemplos e digressões são auxiliares que se tornam de alguma maneira dispensáveis, quando não indesejáveis.

Mas, e quanto às célebres imagens mencionadas? Detenhamo-nos na "razão orgânica", expresão utilizada por Kant em pelo menos duas ocasiões: a introdução aos Prolegômenos (1783) e o segundo prefácio à Crítica da razão pura (1787). Em ambos os casos, textos preliminares, que delineiam o escopo em que se dará a argumentação mais cerrada das respectivas obras. Ao que tudo indica, em ocasiões como essas o filósofo poderia relaxar os ditames de sua exposição escolástica, pois se trata de recomendar a obra ao leitor, de atraí-lo para ela. Seja como for, vejamos o que isso lhe faculta.

Começaremos pelo texto dos Prolegômenos:

A razão pura é uma esfera (Kreis) de tal modo à parte, tão completamente unificada em si, que não se pode tocar em nenhuma parte sem afetar todas as outras, que nada se pode fazer sem primeiramente ter determinado o lugar (Platz) de cada uma e a sua influência sobre a outra (KANT, 1988, p. A 19).

A razão pura é uma esfera: a conformação desse objeto é tal que ele pode ser examinado de maneira completa e exaustiva - ao contrário de outros objetos que, por serem demasiado particulares ou excessivamente gerais, não se deixam apreender numa investigação tal como essa. $\mathrm{O}$ uso do termo esfera é suficiente para sugerir que é a própria razão que se examina criticamente: basta lembrar que alhures Kant se refere aos objetos que estão ao alcance da razão como estando dentro de seu "círculo-de-visão» (Gesichtskreis) (KANT, 1985a, p. A 508): a esfera da razão é a um só tempo sua extensão e seu limite.

O texto prossegue:

Porque nada existe fora [da razão] que possa corrigir o nosso juízo interior, a validade e o uso de cada parte depende da relação em que ela se encontra com as outras na própria razão, tal como na estrutura de um corpo organizado, o fim de cada membro só pode deduzir-se do conceito geral do todo (Ganzen) (KANT, 1988, p. A 19-20).

Entende-se agora que o «lugar» em que se encontra cada uma das «partes» da razão não é aleatório, mas indica a posição de cada uma partes em 


\section{6}

relação a outra, perfazendo juntas um mesmo «todo» (Ganz). Portanto, dizer que a razão é como uma esfera é uma maneira de sugerir que a nossa inteligência tem algo do caráter de uma «estrutura» tal como a de um «corpo organizado», encerra-se sobre si mesma e se define pelas relações necessárias e recíprocas das partes que a compõem ${ }^{3}$.

Reencontramos aqui algo de que a Crítica da razão pura já falava em suas páginas finais: que o "círculo da razão só encontra acabamento num todo sistemático subsistente por si mesmo" (KANT, 1987, p. B 825). Circularidade, sistematicidade e organicidade são termos que remetem ao caráter da razão pura, objeto que interessa ao filósofo investigar. A Crítica da razão pura pretende investigar a razão exaustivamente: é preciso mostrar que um exame como esse é viável, que a razão se presta a uma compreensão exaustiva de si mesma. Talvez para sublinhar desde o início aquilo que o "Cânon da razão pura" indicará de maneira algo discreta, Kant tenha considerado retomar esse mesmo vocabulário logo no prefácio que elabora à segunda edição da Crítica da razão pura:

A natureza da razão é tal que ela encerra uma verdadeira estrutura em que tudo é órgão, isto é, em que tudo existe para cada parte e cada parte para todas as outras, pelo que, qualquer defeito, por mais ínfimo, quer seja engano (erro), quer seja lacuna, logo se denunciaria inevitavelmente no uso (KANT, 1987, p. B XXXVII).

Para convencer seu leitor de que é assim, Kant deveria provar o que a imagem sugere. Mas algo que não se encontra na Crítica da razão pura é a demonstração do caráter orgânico da razão - trata-se pura e simplesmente de evocar algo a respeito da nossa faculdade racional: que a consideração de cada um dos princípios do conhecimento há de mostrar a interdependência entre as suas respectivas legislações e domínios. Desse modo veremos que as diferenças de princípio entre razão, entendimento e faculdade-de-julgar nos constrangem a reconhecer que cada uma das faculdades superiores opera tendo em vista um interesse próprio que nos reenvia, por uma via ou por outra, ao interesse da outra. Ou seja, temos aqui a imagem de uma estrutura completa, encerrada em si mesma, em que tudo é órgão, passível de uma investigação completa e exaustiva. Isso diz respeito à própria viabilidade do projeto crítico; como explica Lebrun: 
A exaustividade do sistema da razão não resulta tanto da excelência do método quanto do fato de que a razão possui um perímetro percorrível - da possibilidade de totalização, de um conjunto limitado. A "perfeição" da Crítica é devida à limitação natural de seu domínio; ela pode aspirar à completude de um sistema, não porque ela prejulga a capacidade do espírito humano, mas porque ela concerne a um potencial desde sempre mensurável (LEBRUN, 1991, p. 42).

O elemento orgânico proposto na imagem parece ser, portanto, acessório do elemento estrutural e sistemático. É o que se pode depreender do fato de que Kant oferece uma variação da tópica da razão como sistema na qual a estrutura da faculdade racional é descrita em termos artísticos, tal como nesta passagem da Dialética transcendental:

A razão humana é, por natureza, arquitetônica, isto é, considera todos os conhecimentos como pertencentes a um sistema possível, e, por conseguinte, só admite princípios que, pelo menos, não impeçam qualquer conhecimento dado de coexistir com outros (KANT, 1987, p. B 502).

A exigência da coexistência entre diferentes princípios nos limites de uma mesma armação é retomada aqui em termos que sugerem uma imagem mecânica, o edifício da razão sendo construído segundo um cálculo que leva em consideração o ajuste entre as partes que o compõem. Mas essa assimilação é ligeira, e desconsidera que a arquitetônica é uma arte: "a arte dos sistemas", que comporta assim uma referência ao que há na razão de propriamente orgânico:

O todo é um sistema organizado (articulado) e não um conjunto desordenado (coacervatio); pode crescer internamente (per intussusceptionem), mas não externamente (per oppositionem), tal como o corpo de um animal, cujo crescimento não acrescenta nenhum membro, mas, sem alterar a proporção, torna cada um deles mais forte e mais apropriado aos seus fins (KANT, 1987, p. B 861).

Encontramos nessa passagem um exemplo da fineza argumentativa de Kant. A definição do todo como sistema organizado e progressivo é apresentada em contraste com aquilo que ele não é, um conjunto desordenado que se expande para além de si mesmo. Introduz-se então uma analo- 


\section{8}

gia, que ilumina a definição comprando a faculdade racional a um corpo animal, pondo lado a lado o todo da razão e o todo orgânico. Uma coisa é falar numa "unidade técnica" dos conhecimentos, que é acidental porque depende da reunião de elementos empíricos "cujo fim não se pode saber de antemão"; outra é fundar "uma unidade arquitetônica", "onde a razão nos fornece os fins a priori e não os aguarda empiricamente". Corpo orgânico e edificio: uma mesma unidade da razão, que se expande sem jamais ultrapassar os seus próprios limites, os contornos se dilatam, a forma permanece a mesma ${ }^{4}$. A clareza estética está a serviço da clareza lógica.

Cabe então a pergunta: haveria um princípio transcendental que oferece a Kant um parâmetro seguro para a linguagem metafórica numa obra de filosofia? Ora, se a exposição escolástica tem sua justificação filosófica, deve haver uma regra transcendental de regulação das imagens na exposição do discurso filosófico (KANT, 1987, p. B XXIV). É o que confirma o texto do $\ 59$ da Crítica da faculdade-de-julgar, intitulado «Do belo como símbolo da eticidade». Ali, Kant diz o seguinte:

O modo-de-representação intuitivo pode ser dividido em esquemático e em simbólico. (...) Todas as intuições que submetemos a conceitos a priori são ou esquemas ou símbolos, os primeiros contendo exposições (Darstellungen) diretas de conceitos, e os segundos, exposições indiretas. Esquemas procedem por demonstração, símbolos por analogia (para as quais nos servimos também de intuições empíricas). Em cada um deles, a faculdade-de-julgar cumpre uma função: aplicar o conceito ao objeto de uma intuição sensível, ou então aplicar a regra da reflexão sobre a intuição a um objeto totalmente diverso desta (KANT, 1992a, B 256).

Essa distinção tem conhecidas implicações conceituais; ela se refere às diferentes espécies de representação, que concernem a razão teórica (esquematismo da imaginação) e a razão prática (típica da razão) ${ }^{5}$. Para nossos propósitos, ela explica que uma imagem, tal como a da «razão orgânica», é para Kant um símbolo que a faculdade-de-julgar encontra para iluminar o conceito da razão como todo no plano argumentativo da Crítica.

Kant explica que, ao falarmos em “Estado monárquico”, podemos nos referir a ele como uma máquina, sendo despóticas as leis que o gove r- 
nam, ou como um organismo, sendo populares as suas leis (KANT, 1992a, B 256). Sabemos por outros textos que se a meta do despotismo é manter a sujeição do povo ao monarc a, o monarca ilustrado oferece a possibilidade de esclarecer o povo a ponto de este se tornar legislador por si mesmo ${ }^{6}$. Não por outra razão, a oposição figurada entre «mecânico»e «orgânico» enquanto princípios de legalidade já aparecia no texto O que é ilustração. Ali, "preceitos e fórmulas» são ditos «instrumentos mecânicos do uso da razão, ou melhor, do mau uso de nossos dons naturais» (KANT, 1985c, p. A 482-3). P receitos mecânicos são estranhos à razão como faculdade dos princípios do conhecimento, e só lhe servem numa dimensão instrumental que não deve ser confundida com a instância em virtude da qual a razão se torna legisladora. Essa confusão resulta na condição que Kant chama de «heteronomia»: a condição «natural» (naturliche) do «entendimento sadio» é ao contrário «autonomia». A razão, quando se orienta exclusivamente por seus próprios princípios, se constitui a si mesma integralmente a partir de si mesma: torna-se uma «estrutura orgânica», poderíamos dizer (KANT, 1985c, p. A 483-4).

Como bem mostram esses exemplos, o uso figurativo da linguagem pode muito bem se imiscuir no discurso filosófico sem trazer confusão para o seu interior nem torná-lo obscuro; Kant reafirma o poder esclarecedor da metáfora, ao qual o próprio Aristóteles já se referia como indispensável para o bom argumento racional (ARISTÓTELES, 1998, p. 1404b). A clareza estética complementa a clareza lógica, que por seu turno a justifica. Como explica Kant,

Nossa linguagem está repleta de semelhantes exposições indiretas, segundo uma analogia, nas quais a expressão não contém o esquema próprio para o conceito, mas simplesmente um símbolo para a reflexão (KANT, 1992a, p. B 257).

Encontramos aqui, numa constatação que vale tanto para o uso ordinário da linguagem quanto para o seu uso filosófico - que é, como assinala Kant a propósito de Locke, repleto de subrepções imagéticas, - a justificação mais rigorosa da metáfora que nos interessa: «a razão orgânica». Trata-se de um símbolo, para aquela espécie de reflexão que cabe ao filósofo crítico realizar - a reflexão da razão sobre si mesma. Sem nos dar algo a conhecer (a razão não é um organismo), esse recurso nos faculta 
um análogo de intuição da natureza do objeto que nos interessa considerar, ao qual «nenhuma intuição jamais poderia corresponder diretamente» (KANT, 1992a, p. B 257).

Seria um equívoco discursar em linguagem exclusivamente simbólica, que se sobrepõe à clareza lógica, e por isso a regulação dos símbolos é tarefa indispensável para o filósofo crítico (SUZUKI, 1998, p. 57; 73). O que a Crítica oferece, ao falar numa "razão orgânica", é o exemplo de como proceder no interior da linguagem de modo a torná-la subserviente aos fins da razão, ou ao estabelecimento da filosofia como ciência. Reconhece-se aqui o entrelaçamento originário entre a nova disciplina filosófica e o cultivo da arte retórica, que desde Aristóteles, atrai aqueles interessados em expressar sentimentos humanos pela linguagem ${ }^{7}$.

A elegância da imagem proposta por Kant dá testemunho não apenas de sua deferência para com o leitor mas também do talento desse filósofo, que foi também um grande escritor, no cultivo da «bela-arte da eloqüência e do bem-dizer» (KANT, 1992a, p. B 257), arte que responde, no seio da linguagem técnica, à exigência de rigor inerente à filosofia como sistema sem jamais abandonar a lógica como fio-condutor (Leitfaden) que permite constituí-la como ciência (Wissenschaft). Diante disso, não parece surpreendente constatar agora que o uso metafórico da linguagem corresponde rigorosamente àquilo que a terceira Crítica chama de «idéia estética»,

Uma representação da imaginação que acompanha um conceito dado e que está vinculada a uma tal diversidade de representações parciais em seu uso livre, que para ela não pode ser encontrada nenhuma expressão que designe um conceito determinado, e que, portanto, permite acrescentar em pensamento a um conceito muito de indizível, cujo sentimento vivifica a faculdade de conhecer e vincula à linguagem, como mera letra, um espírito (KANT, 1974, \49) ${ }^{8}$.

Kant oferece um princípio transcendental de regulação da linguagem metafórica. Inserida num discurso de teor filosófico, uma metáfora não é mais que o símbolo de um conceito dotado de um esquema próprio, mas 
cuja significação é passível de um alargamento capaz de sugerir, a seu respeito, algo mais que o conteúdo estritamente vinculado a ele. Com isso, Kant afasta a suspeita de que o discurso conceitual ou da filosofia dependeria de uma fundação metafórica. Ao contrário, a filosofia crítica mostra que toda linguagem se justifica, em última análise, por referência a uma instância do pensamento a qual Kant dá o nome de transcendental, capaz de regular a significação das palavras no interior de um discurso tal que responde às exigências da faculdade racional como um todo - pensar e conhecer, sem dúvida, mas também enunciar aquilo que se pensa, conhece ou sente.

Encontramos o mais proficuo aprofundamento dessas considerações nos melhores leitores de Kant, ou em seus seguidores mais imediatos. Poderíamos pensar em Fichte, às voltas com o descompasso entre a imaginação transcendental e suas configurações empíricas, mas também em Schelling, que, partindo de uma indagação semelhante, chega a resultados inteiramente originais e que permanecem fiéis, ao menos quanto às intenções, ao espírito que anima a filosofia kantiana. Uma das inovações radicais dos pós-kantianos consiste em atribuir à imaginação podere s próprios que se confundem, em certa medida, com os do julgar kantiano em sua reflexão; isso é o suficiente para que se abra todo um campo de especulação apenas sugerido pela Crítica da razão pura.

É o que se percebe quando Schelling, no Sistema do idealismo transcendental (1800), define "conceito" como "regra de construção de um objeto em geral" e "objeto como expressão da regra mesma" pela qual ele foi construído; do que se depreende que o esquema da imaginação não é mais que "o ato" no qual "a regra é intuída como objeto" e o "objeto é intuído como regra". O esquematismo, define Schelling, é uma "intuição" (Anschauung), não de objetos ou de conceitos, mas de uma "regra"

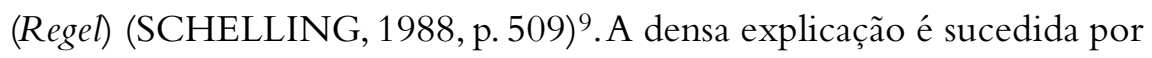
um esclarecimento que se dá por meio de um exemplo: "o artista mecânico, que produz um objeto de forma determinada, de acordo com um conceito":

O que o [artesão] comunica [à matéria] é o conceito do objeto. Mas não se vê como, a partir de um modelo externo, poderia uma forma se originar paulatinamente em suas mãos, unida ao conceito, não fosse por uma regra intuída internamente, ainda que de modo sensível, a guiá-lo 


\section{2}

na produção (Hervorbringung) do objeto. Tal regra é o esquema, no qual não está contido nada de individual e que tampouco é um conceito geral a partir do qual o artista nada poderia produzir (SCHELLING, 1988, p. 509).

Essa bela passagem, que resume com limpidez o papel da imaginação no esquematismo segundo o entende Schelling, sugere coisas interessantes a respeito da leitura das páginas que Kant dedica ao esquematismo transcendental na primeira Crítica; mas também pode ser lida como um comentário ou variação do que diz Kant na arquitetônica da Crítica da razão pura, quando se trata de explicar "o mistério do esquematismo". O que é uma arquitetônica da razão pura? É "a arte de construir sistemas". Qual a condição dela? Um “esquema” que contém a priori o princípio de elaboração de um sistema segundo os fins da razão. Unidade arquitetônica de um sistema é o resultado de um esquema esboçado segundo os fins da razão, esquema esse que, enquanto "monograma” do todo, contém já a divisão formal das partes dos sistema tal como sugerida por uma idéia da razão (KANT, 1987, p. B 825). Mas o que é o filósofo crítico, senão o artesão dos sistema da razão pura? E o que é sua idéia, senão o modelo que ele deve imitar se quiser obter um esquema que, sem determinar nada em particular, e sem nada intuir, se refere a uma articulação em geral, segundo princípios da razão? O sistema de uma filosofia tal como a de Kant é tão-somente o resultado de uma arte de sensibilizar ao leitor a unidade apenas inteligível da razão: literalmente, a arte de "trazer à vista" (Hervorbringen) uma idéia.

Mas expor, é nesse sentido, mais precisamente, pôr em palavras: a idéia de que se trata, a de um sistema filosófico que corresponde a uma estrutura previamente dada (a razão orgânica), deve ser construído pelo filósofo, na sensibilidade, por meio da composição de um discurso. Por isso, se Schelling vai além de Kant, permanece fiel no que mais importa. Concebe o esquematismo como uma intuição e afirma que dessa intuição indeterminada depende "o mecanismo inteiro da linguagem", como comprova o fato de que sua doutrina do esquematismo permite explicar a estrutura das línguas primitivas, as opiniões mais antigas acerca da natureza e as narrativas mitológicas que nos foram legadas por diferentes povos (SCHELLING, 1988, p. 510). E arremata a explicação do esquema 
dizendo que o esquematismo está para os conceitos tal como o simbolismo está para as idéias: refere-se sempre à forma de um objeto empírico, enquanto que o simbolismo diz respeito à forma de um objeto excogitado em idéia (SCHELLING, 1988, p. 510-11). E, por mais que a doutrina de Schelling não coincida exatamente com a de Kant, mantém-se intacta a correlação estabelecida no $\ 49$ da Crítica do Juízo, acima citado: a verdadeira arte, no sentido estético, é simbólica por definição. E o filósofo, enquanto artesão da linguagem, tem com ela uma relação limitada: posto que o esquematismo, e não o simbolismo, é que está na base da linguagem, esta só pode simbolizar quando elabora símiles e metáforas, quando a clareza estética vem auxiliar e reforçar a clareza lógica que é a alma da exposição.

Essa rápida retomada da doutrina do esquematismo em Schelling é suficiente para compreender porque mais à frente, no mesmo Sistema do idealismo transcendental, quando se trata de deduzir "as proposições" que respondem por uma "teleologia segundo princípios transcendentais", ele irá encontrar na "forma orgânica" a forma "figurada" (figurlich) da liberdade: interpretando o organismo, "deciframos (Chiffernschrift) o fenômeno da liberdade em nós mesmos". Assim como em Kant, o organismo é uma forma ou idéia que, unida a conceitos de liberdade e necessidade, dá o que pensar: por exemplo, que o atuar livre apenas separa o que no produto natural se encontra unido, o rastro inequívoco de uma intencionalidade e a confirmação inegável das leis necessárias da natureza (SCHELLING, 1988, p. 608). Cabe ao filósofo, com seu pendor de artista, explorar as possibilidades que se abrem a partir dessa sugestão, "decifrando", ou interpretando os caracteres desse texto que é o organismo, e que proclamam, de maneira figurada (isto é: textualmente), uma verdade mais essencial, em benefício dos interesses da razão. A conclusão desta nova filosofia transcendental? Que "toda organização é um monograma de uma identidade originária” (SCHELLING, 1988, p. 611). Schelling confirma assim que a filosofia de Kant está para a sua própria como se fora uma idéia estética, no sentido kantiano, um modelo geral e indeterminado, um texto que incita, a partir da letra, a reflexão em busca de um espírito. 
A vida das imagens, a exemplo daquela das idéias, se estende para além dos limites dentro dos quais surgem. Trabalhadas por outros autores, adquirem novas feições e são postas para operar em contextos que redefinem o seu significado, o seu poder metafórico. E, assim como quem primeiro as formulou não tem mais controle sobre elas, nem sempre quem delas se apropria consegue conter o poder sugestivo que elas têm. A metáfora kantiana da "razão orgânica" encontra uma posteridade das mais fecundas justamente nas mãos de um dos leitores mais mordazes de Kant. Em Pa ra além de bem e mal, Nietzsche tece uma imagem que se inscreve diretamente no campo semântico estabelecido por Kant. Comentando a suposta perenidade da filosofia, Nietzsche diz o seguinte - na tradução de Paulo César de Souza:

Os conceitos filosóficos individuais não são algo fortuito e que se desenvolve por si, mas crescem em relação e em parentesco um com o outro; embora surjam de modo aparentemente repentino e arbitrário na história do pensamento, não deixam de pertencer a um sistema, assim como os membros da fauna de uma região terrestre - tudo isto se confirma também pelo fato de os mais diversos filósofos preencherem repetidamente um certo esquema básico (Grundschema) de filosofias possíveis. À mercê de um encanto invisível, tornam a descrever sempre a mesma órbita (Kreisbahn): embora se sintam independentes uns dos outros com sua vontade crítica ou sistemática, algo neles os conduz, alguma coisa os impele numa ordem definida, um após o outro - precisamente aquela relação sistemática e inata entre os conceitos (NIETZSCHE, 1992, \$20) ${ }^{10}$.

A significação dos conceitos depende de relações de parentesco entre eles no interior de uma linguagem dada. Pertencem a um mesmo sistema, que se repete nos diferentes enunciados de cada filósofo. A sucessão dos sistemas de pensamento, à mercê de um "encanto invisível", nos leva sempre de volta ao ponto de partida. Ao reconhecer uma relação sistemática e inata entre os conceitos, Nietzsche encontra na história da filosofia uma "o rdem definida" que é o revés de uma ordenação teleológica. $O$ sentido dessa ordem se encontra em sua enunciação. Daí a 
retomada deliberada do vocabulário kantiano: é preciso dissecar a linguagem, inclusive o uso figurado das palavras, para encontrar o sentido dos $\operatorname{conceitos}^{11}$. Nietzsche continua a variar o ideário kantiano: do que depende a história da razão pura, segundo a Crítica, senão dessa monotonia que rege o desfile dos sucessivos sistemas filosóficos, desde Platão até Hume? O historiador da filosofia não faz mais do que reafirmar esse "esquema fundamental" a despeito da aparente variedade e incompatibilidade dos diferentes sistemas. A crítica não é de livros, insiste Kant, mas sim da razão pura como um todo (KANT, 1987, p. A VIII).

Mas sabemos que Nietzsche não se resigna a isso. A chave do mistério do "esquema fundamental" que se encontra em toda filosofia, que dá à história dessa disciplina um certo ar de "atavismo", ele encontra no estudo da gramática - essa disciplina que está, segundo Kant, para a linguagem, assim como a lógica está para o pensamento (KANT, 1992b, Introdução). A constatação (nietzscheana) de que a filosofia torna a descrever, em linguagem figurada, a mesma "órbita", o mesmo "círculo", a "estrutura" que é a da nossa faculdade racional; a confirmação de um mesmo"esquema", nas palavras de cada um dos filósofos, em todas as épocas, é o que nos permite falar, com Kant, numa história da filosofia como parte de uma crítica da razão; é o que permitirá, mais tarde, que se delineie e se pratique, na universidade, uma disciplina filosófica chamada história da filosofia. Em Nietzsche, o eterno retorno do mesmo sugere outras espécies de exercício, e tais que põem em xeque a legitimidade ou mesmo a pertinência dessa disciplina, seja ela kantiana ou acadêmica, mas que talvez não sejam tão estranhos às intenções da Crítica. $\mathrm{O}$ próprio Kant reconhecia que, mesmo quando utilizada como um jargão vazio, na boca de filósofos irresponsáveis, a língua da filosofia trai, de alguma maneira, a estrutura da razão. O curto-circuito semântico, o descompasso entre o que dizemos e o que pensamos, a falta de sentido, uma vez enunciada, é por si mesma um indicativo suficiente de que em toda e qualquer enunciação há, por definição, uma racionalidade, ainda que deturpada e operando às cegas: é preciso desvendá-la, criticar a linguagem remetendo-a a conceitos (KANT, 1985d, p. 94). E, diante da importância que tem para Kant a leitura dos textos e a regulação transcendental do vocabulário da filosofia, não seria surpreendente se encontrássemos agora, na filologia, a propósito da leitura de Nietzsche, um dos possíveis prolonga- 
mentos da crítica. O que talvez possa explicar este estranho desfecho: que a Crítica de Kant tenha se tornado, ao lado da Genealogia de Nietzsche, um objeto de estudo, e exatamente no mesmo sentido em que ela tomava os sistemas de metafísica: como mais um exemplo, singular e permanente, das condições subjetivas do uso dessa estrutura, orgânica ou não, que é a nossa razão.

1 Comunicação apresentada no colóquio "Estrutura, subje tividade e sistema", ocorrido na Université Blaise Pascal (Clermont-Ferrand, França) em setembro de 2006.

2 Ver ainda Kant (KANT, 1992b, A 229) sobre a diferença entre "sistema escolástico" e "sistema popular".

${ }^{3}$ A forma do texto dos Prolegômenos que estamos comentando contribui para construir a imagem que Kant tem em vista. O primeiro movimento é de circunscrição: a razão é ... "de tal modo à parte"... "tão completamente unificada" ... que "não se pode tocar" ... "nada se pode fazer" ... "sem antes" ... "determinar o lugar". O início da segunda parte da oração (..."porque, nada existindo fora dela”...) acentua o caráter necessário e quiçá inalterável dessa "estrutura".

${ }^{4}$ Encontramos aqui uma variação da comparação entre os corpos orgânicos e os edifícios que remonta a Vitrúvio, De architectura, III.i.3. Burke se refere a esse tópico como uma "analogia forçada", a forced analogy (BURKE, 1990): parte III, seção 04. Daniel Lago Monteiro chamou minha atenção para essa passagem.

${ }^{5}$ Ver Rubens Rodrigues Torres Filho (TORRES FILHO, 2004).

${ }^{6}$ Ver Kant (KANT, 1985b, p. B $\left.78-79\right)$.

${ }^{7}$ Não deveria então o filósofo, em sua prática textual, espelhar-se no modelo que lhe oferece a faculdade produtiva da bela-arte tomada no plano antropológico? "Espírito e gosto: o primeiro para criar idéias, o segundo para limitá-las à forma adequada às leis da imaginação produtiva e, assim, formá-las (figendi)originalmente (não imitativamente)" (KANT, 2006, \$71 B).

8 Cf. o comentário de Lebrun: «Ali onde a palavra representação é compreendida (como em Kant, por exemplo) na classe restritiva da exhibitio (Darstellung), somos forçosamente levados a distinguir duas regiões: o que é apresentação da própria coisa e o que é indicação por substituição. Essa repartição, então, parece impor-se naturalmente ». (LEBRUN, 2006, p. 444 - 45).

${ }^{9}$ Cotejamos o texto com o original alemão.

10 Agradeço a Márcia Rezende, que primeiro chamou a minha atenção para esse texto, comentado por ela num excelente seminário.

11 Como observa Carlos Alberto Ribeiro de Moura a propósito do método de Lebrun, que tanto deve a Kant, teríamos na "história da filosofia uma atividade bem mais próxima da crítica literária do que de qualquer ciência positiva" (RIBEIRO DE MOURA, 2006, p. 11).

doispontos, Curitiba, São Carlos, vol. 5, n. 1, p.123-138, abril, 2008 


\section{Referências bibliográficas:}

ARISTÓTELES. 1998. Retórica. Tradução e notas de Manuel Alexandre

Jr., Paulo F. Alberto e Abel do Nascimento Pena. Lisboa: Casa da Moeda.

BURKE, E. 1990. A philosophical inquiry concerning the original of our ideas of the sublime and beautiful. Oxford: University Press.

KANT, I. 1987. Crítica da razão pura, A XVII. Tradução de Manuela

Pinto dos Santos e Artur Fradique Morujão. 2a edição. Lisboa:

Fundação Calouste-Gulbenkian.

KANT, I. 1988. Prolegômenos a toda metafísica futura, A 19. Tradução de Artur Morão. Lisboa: Edições 70.

KANT, I. 1985a. "O fim de todas as coisas". In: Textos seletos. Tradução de Floriano S. Fernandes. 2a edição. Petrópolis:Vozes.

KANT, I. 1992a. Crítica da faculdade do juízo. Tradução de Antonio Marques e Valério Roden. Lisboa: Casa da Moeda.

KANT, I. 1985b. "Sobre a discordância entre a moral e a política a propósito da paz perpétua”. In: Textos seletos. Tradução de Floriano S. Fernandes. 2a edição. Petrópolis:Vozes.

KANT, I. 1985c. “Resposta à pergunta: que é ilustração?”. In: Textos seletos. Tradução de Floriano S. Fernandes. 2a edição. Petrópolis:Vozes.

KANT, I. 2006. Antropologia de um ponto de vista pragmático. Tradução de Clélia Martins. São Paulo: Iluminuras.

KANT, I. 1974. Crítica do Juízo. Tradução de Rubens Rodrigues Torres Filho. In: Os pensadores vol. XXV. São Paulo: Abril.

KANT, I. 1992b. Lógica. Tradução: Guido Antonio de Almeida. Rio de Janeiro: Tempo Brasileiro.

KANT, I. 1985d. “Que significa orientar-se no pensamento?”. In: Textos seletos. Tradução de Floriano S. Fernandes. 2a edição. Petrópolis:Vozes.

LEBRUN, G. 1991. Kant e o fim da metafísica. Tradução Carlos Alberto de Moura. São Paulo: Martins Fontes. 
LEBRUN, G. 2006. «A noção de semelhança de Descartes a Leibniz». Tradução de Michel Lahud. In: A filosofia e sua história. São Paulo:

Cosac \& Naify.

NIETZSCHE, F. 1992. Para além de bem e mal. Tradução de Paulo César de Souza. São Paulo: Companhia das Letras.

RIBEIRO DE MOURA, C. A. 2006. "Apresentação” a Gérard Lebrun, A filosofia e sua história. São Paulo: Cosac \& Naify.

SCHELLING, F. W. J. 1988. Sistema del idealismo transcendental. Tradução Rosales y Dominguez. Barcelona: Anthropos.

SUZUKI, M. 1998. O gênio romântico. Crítica e história da filosofia em Friedrich Schlegel. São Paulo: Iluminuras.

TELLES, L. F. 1998. “A estrutura da bolha de sabão”. In: O conto brasileiro contemporâneo. Org. Alfredo Bosi. 11ª edição. São Paulo: Cultrix. TORRES FILHO, R. R. 2004. “O simbólico em Schelling”. In: Ensaios de filosofia ilustrada. $2^{\text {a }}$ edição. São Paulo: Iluminuras. 